\title{
A Triple-Stage Algorithm for Optimal Unit Scheduling of Thermal Units
}

\author{
Sen-Nien Yu, and Yuan-Kang Wu
}

\begin{abstract}
Scheduling the economic generation of thermal units is a critical task in a large scale power system because it significantly reduces annual production cost. This study presents a novel triple-stage algorithm to solve the problem of combining unit commitment and economic dispatch of the thermal units while minimizing cost. The proposed algorithm divides all the units into five groups and finds potential combinations with a redundancy factor in the first stage. Then, employ a simplified economic dispatch method and a look forward method to obtain the optimal unit scheduling in the second stage. Lastly, a look backward method is applied to refine the optimal solution in the last stage. When the discontinuous cost function of unit is considered, a zero cost power method is also used to evaluate the solution. Finally, three test cases are simulated and the results compared with existing methods. Simulation results demonstrate the outstanding performance of the proposed method.
\end{abstract}

Index Terms - Unit commitment, generation dispatch, discontinuous cost function, ramp rate constraint.

\section{REFERENCES}

[1] A. J. Wood, and B. F. Wollenberg, Power Generation Operation and Control, New York: John Wiley and Sons, 1984, pp. 110-121.

[2] S. Virmani, C. Adrian, K. Imhof, and S. Mukherjee, "Implementation of a Lagrangian relaxation based unit commitment problem," IEEE Trans. Power Systems, vol. 4, pp. 1373-1380, Oct. 1988.

[3] Z. Ouyang, and S. M. Shahidehpour, "An intelligent dynamic programming for unit commitment application,” IEEE Trans. Power Systems, vol. 6, pp. 1203-1209, Aug. 1991.

[4] W. J. Hobbs, G. H. S. Warner, and G. B. Sheble, "An enhanced dynamic programming approach for unit commitment,” IEEE Trans. Power Systems, vol. 3, pp. 1201-1205, Aug. 1988.

[5] C. L. Chen, and S. C. Wang, "Branch-and-bound scheduling for thermal generating units,” IEEE Trans. Energy Conversion, vol. 8, pp. 184-189, June 1993.

[6] S. A. Kazarlis, A. G. Bakirtzis, and V. Petridis, ”The genetic algorithm solution to the unit commitment,” IEEE Trans. Power Systems, vol. 11, pp. 83-92, Feb. 1996.

[7] K. A. Juste, H. Kita, and J. Hasegawa, ”An evolutionary programming solution to the unit commitment problem,” IEEE Trans. Power Systems, vol. 14, pp. 1452-1459, Nov. 1999.

[8] H. T. Yang, P. C. Yang, and C. L. Huang, ”A parallel genetic algorithm approach to solving the unit commitment problem: implementation on the transputer networks,” IEEE Trans. Power Systems, vol. 12, pp. 661668, May 1997.

[9] J. C. Christiansen, C. A. Dortolina, and J. F. Bermudez, ”An approach to solve the unit commitment problem using genetic algorithm," IEEE Trans. Power Systems, vol. 11, pp. 261-266, Feb. 2000.

[10] K. S. Swarup, and S. Yamashiro, "Unit commitment solution methodology using genetic algorithm,” IEEE Trans. Power Systems, vol. 17, pp. 87-91, Feb. 2002.

[11] P. Attaviriyanupap, H. K. E. Tanaka, and J. Hasegawa, "A hybrid EP and SQP for dynamic economic dispatch with nonsmooth fuel cost function,” IEEE Trans. Power Systems, vol. 17, pp. 411-416, May 2002.

[12] H. Saadat, Power System Analysis, New York: McGraw-Hill, 1999, pp. 272-275.

[13] W. M. Lin, F. S. Cheng, and M. T. Tsay, ”Nonconvex economic dispatch by integrated artificial intelligence," IEEE Trans. Power Systems, vol. 16, pp. 307-311, May 2001.
[14] D. C. Walters, and G. B. Sheble, "Genetic algorithm solution of economic dispatch with valve point loading," IEEE Trans. Power Systems, vol. 8, pp. 1325-1331, Aug. 1993.

[15] T. A. A. Victoire and A. E. Jeyakimar, "Unit commitment by a tabusearch-based hybrid-optimisation technique,” IEE Proceeding Generation, Transmission \& Distribution, Vol.152, No.4, pp.563-574, July 2005.

[16] I. G. Damousis, A.G. Bakirtizis and P. S. Dokopoulos, "A solution to the unit-commitment problem using integer-coded genetic algorithm,” IEEE Trans. on Power Systems, Vol.19, No.2, pp.1165-1172, May 2004.

[17] T. O. Ting, M. V. C. Rao and C. L. Loo, “A novel approach for unit commitment problem via an effective hybrid particle swarm optimization,” IEEE Trans. on Power Systems, Vol.21, No.1, pp.411-418, February 2006.

\section{BIOGRAPHIES}

Sun-Nien Yu was born on April 1966 in Miaoli, Taiwan. He received his B. S. and M. S. degrees in Electric Engineering from National Taiwan Institute of Technology in 1991 and 1993 respectively. Since 1996, he has been with Chung Chou Institute of Technology and he is an associate professor of electrical engineering now. His research interests are in the operation, planning and analysis of power systems. 